International Journal of Linguistics, Literature and Translation

ISSN: 2617-0299 (Online); ISSN: 2708-0099 (Print)

DOI: $10.32996 /$ ijllt

Journal Homepage: www.al-kindipublisher.com/index.php/ijltt

\title{
Repair Practices in Phone Conversations: A Case Study of Chinese English Speakers
}

\author{
Andy, Jiahao LIU1 $8(D) \square$ and Riley, Yiting Peng' 8 (D) \\ ${ }^{1}$ MA in English Studies, Department of English, Faculty of Arts and Humanities, University of Macau, Macau SAR, China \\ ${ }^{2}$ MA in English Studies, Department of English, Faculty of Arts and Humanities, University of Macau, Macau SAR, China
}

$\checkmark$ Corresponding Author: Andy, Jiahao LIU, E-mail: jhliu1999@outlook.com

\author{
ARTICLE INFORMATION \\ Received: September 06, 2021 \\ Accepted: October 14, 2021 \\ Volume: 4 \\ Issue: 10 \\ DOI: $10.32996 /$ ijllt.2021.4.10.5
}

\section{KEYWORDS}

Repair, Conversation analysis, Repair avoidance, Chinese English speakers, Case study

\section{ABSTRACT}

Repair, one key concept in conversation analysis, usually refers to the ways of dealing with troubles of speaking, understanding, and hearing in the talk (Schegloff et al., 1977). This paper focuses on the latter two trouble sources, i.e., troubles of hearing and understanding. The study here, of a dataset of interactions concerning information inquiries between two Chinese learners of English and eight service employees in hotels or airlines, investigates how the repair is initiated and completed via phone through the perspective of conversation analysis. It mainly explores (a) how trouble sources are identified by the recipient over the phone; (b) how the repair is initiated in phone conversations; and (c) how repair strategies and repair avoidance are used based on the recipients' identification of the trouble source type and the importance of the mistake or misunderstanding, in the service industry. The results showcase that Chinese English speakers encounter troubles of understanding and hearing in phone conversations frequently. A selection of initiators and strategies are identified, such as repair preface (e.g., 'I mean') and pre-framing. The analysis also illustrates that the service personnel involved tend to either accept the customer's candidate understanding to avoid the repair or continuously make repairs on their own turns to clarify. Such empirical evidence further supports and validates Kitzinger's (2013) idea that a) specific repair forms and practices are constrained by a range of local factors, and b) people adopt diversified methods and strategies to ' $f$ ix' troubles of hearing and understanding.

\section{Introduction}

Conversation provides foundations for forming direct social relations between people (Allen \& Guy, 1974). Given the advancement of technology, modes of communication for "professional and personal matters" (Wang \& Zhang, 2021) have become increasingly reliant on phones. Gradually, being able to achieve successful communication over the phone is of importance for second language speakers (hereafter, L2 speakers). To put it bluntly, "[l]anguage learners who are unable to engage in fluent phone conversations will be hampered in their dealings in the real world" (Wang \& Zhang, 2021: p.222; italics added). All conversations, however, are potentially subject to difficulties (Liddicoat, 2010). Specifically, Schegloff et al. (1977) categorized these difficulties as "possible trouble in speaking, hearing or understanding". To address these trouble sources, repair is developed to ensure that "the interaction does not freeze in its place when trouble arises" (Schegloff, 2007: xiv).

The present paper seeks to explore how repair is initiated and completed during telephone conversations between customers and service personnel, through the lens of conversation analysis. Participants involved here include two customers recruited through convenience sampling (Dörnyei, 2007) and eight service employees working in hotels or airlines who were recruited randomly. By chance, all of them are L2 speakers of English (i.e., Chinese English speakers in this case). The specificalities of their repairs consist of repair initiators and repair strategies. Through the emphasis on two types of trouble sources (i.e., the trouble of hearing and understanding) in data collected in the service industry, this paper attempts to explore,(i) how trouble sources are identified by

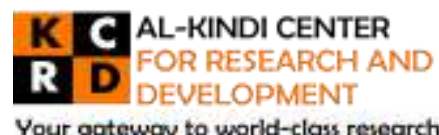

Your gateway to world-class research

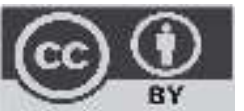

Published by Al-Kindi Center for Research and Development, London, United Kingdom. Copyright (c) the author(s). This open access article is distributed under a Creative Commons Attribution (CC-BY) 4.0 license 
the recipient over the phone; (ii) how repair is initiated in telephone conversations; and (iii) how repair strategies and repair avoidance are used based on the recipient's identification of the trouble source type and the criticality of the mistake or misunderstanding, in the service industry.

\section{Literature Review}

Repair practices refer to the ways of dealing with troubles of hearing, understanding, and speaking in the talk (Schegloff et al., 1977). It should also be noted that the domain of repair extends beyond error correction. Previous research on repair has identified common repair types, initiators, and strategies (cf., Schegloff et al., 1977; Have, 2007; Sidnell, 2010; Kitzinger, 2013).

Essentially, Schegloff et al. (1977) proposed that repair could be initiated by either the speaker (self-initiated repair) or the hearer (other-initiated repair). Between them, other-initiated repairs are usually associated with certain types of repairable items (e.g., troubles of hearing) (Liddicoat,2010). The speaker, however, is possible to initiate the trouble of hearing on his/her own turn. In fact, indicating a problem of hearing can be done explicitly or implicitly (Svennevig, 2008). Svennevig (2008), furthermore, suggested that troubles of understanding can be recognized through the displaying of incomprehension followed with the clarification request.

Additionally, notable efforts have been made to identify the repair initiators and strategies used in conversations. Kitzinger (2013), for example, provided a systematic review concerning the technology of repair, such as repair prefaces (Lerner $\&$ Kitzinger, 2010), open-class initiators (Drew, 1997; Lerner \& Kitzinger, 2015), and cut-offs (Laakso \& Sorjonen, 2010). What's more, Sidnell (2010) briefly introduced the common repair strategies, including framing (see Schegloff, 2004), replacement, deletion, insertion, and reordering.

Following the typical model proposed by Schegloff et al. (1977) in English, repairs have been studied across other languages and L2 speakers, such as Mandarin (Wu, 2006) and Korean (Kim, 2018). Besides, second language acquisition researchers, particularly those with interactionist perspectives, have paid attention to repairs (e.g., Wong, 2000; Hosoda, 2006). For instance, Scarcella (1988) argued that being able to make self-repair and elicit repair from others is critical for second language learners.

However, Kitzinger (2013) argued that repair-specific forms and practices are constrained by a range of local factors. In other words, the repair strategies may present differences across industries and regions. Moreover, the diversified methods people adopt to 'fix' troubles of speaking, hearing, and understanding deserve much more exploration (Kitzinger, 2013; Jefferson, 2003). Motivated to reveal the distinctive repair practices in different industries and to address the call for more exploration aforementioned, we conduct this small-scale case study in the service industry as a potential site to explore the repair practices.

\section{Methodology}

The excerpts examined and analyzed here were drawn from a dataset based on interactions between two Chinese learners of English and eight service employees in hotels or airlines. The two Chinese learners of English were recruited through the convenience sampling method (Dörnyei, 2007). Prior to recording, the first two authors conducted a small survey among their classmates and friends to check whether they had any travel or booking plans. Luckily enough, the two participants here gave confirmed responses and showed their willingness to participate in this study. The two participants then signed the consent form. It also should be noted that the first two authors have requested the two participants to check the permission of recording from the service personnel involved.

The original database comprises eight audios, each lasting 4.5 minutes approximately in length. Following a thorough review of the dataset, 14 fragments were chosen for transcription according to Sidnell's (2010) transcription conventions. These fragments were selected for their representativeness and richness in presenting (i) how trouble sources are identified in the telephone conversations; (ii) how repairs are initiated over the phone; (iii) how repair strategies and repair avoidance are used based on the recipient's identification of the trouble source type and the criticality of the mistake or misunderstanding. 


\section{Results and Discussion}

The present paper concerns the repair that happens between the caller (customer) and the operator (service personnel) concerning information inquiries. We display the analysis in five instalments based on the types of trouble source and their development, as presents in Table 1.

Table 1 General descriptions and the types of trouble source in the excerpts

\begin{tabular}{|l|l|}
\hline Excerpt 1 & $\begin{array}{l}\text { General description: The operator inquiries about the check-in and check-out information with the } \\
\text { male caller. } \\
\text { Type: Trouble of hearing }\end{array}$ \\
\hline $\begin{array}{l}\text { Excerpt 2 \& } \\
\text { Excerpt 3 }\end{array}$ & $\begin{array}{l}\text { General description: The operator seeks information of preferred bed types from the male in Excerpt } \\
\text { 2; the operator asks the male's potential 'sand resort club member' information in Excerpt 3. } \\
\text { Types: Moving from the trouble of hearing to the trouble of understanding }\end{array}$ \\
\hline $\begin{array}{l}\text { Excerpt 4 \& } \\
\text { Excerpt 5 }\end{array}$ & $\begin{array}{l}\text { General description: The operator enquiries the male's staying period in Excerpt 4; the operator } \\
\text { confirms the female's check-in date in Excerpt 5. } \\
\text { Types: Trouble of understanding }\end{array}$ \\
\hline
\end{tabular}

\subsection{Troubles of Hearing}

Due to the fact that the telephone conversations are limited to "sounds, split from actions [i.e., postures, gestures or facial expressions]" (Hopper,1992: P8), L2 speakers are frequently encountering troubles of hearing (Schegloff et al.,1977; Have, 2007). Here in Excerpt 1, we present how the operator addresses the problem of hearing (Svennevig, 2008) when the male is requesting him/her to raise the voice volume. Line 1 clearly shows the operator's unclear and low voice when he/she is making a request for information.

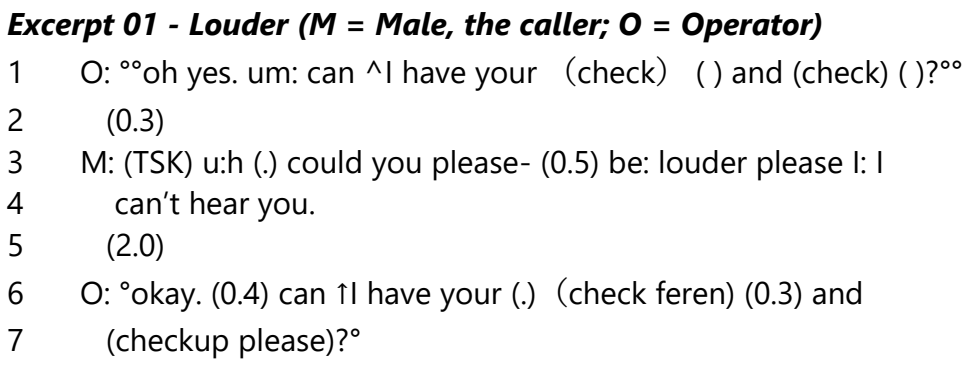

In response to the operator's question (line 1), the male here demonstrates some difficulties in hearing (lines 2-4) as evidenced by the short pause and the direct request 'could you please be louder?'. After a long pause lasting for 2 seconds, the operator notices this problem of hearing initiated from the male. To address it (lines 6-7), the operator first offers a confirmatory response 'okay' to show his/her understanding and agreement and then repeats the question in a louder voice.

Excerpt 1 displays how the operator handles the problem of hearing when direct requests are made. However, the situation becomes more complicated in Excerpt 2, where the operator inquiries about the customer's preferred bed types.

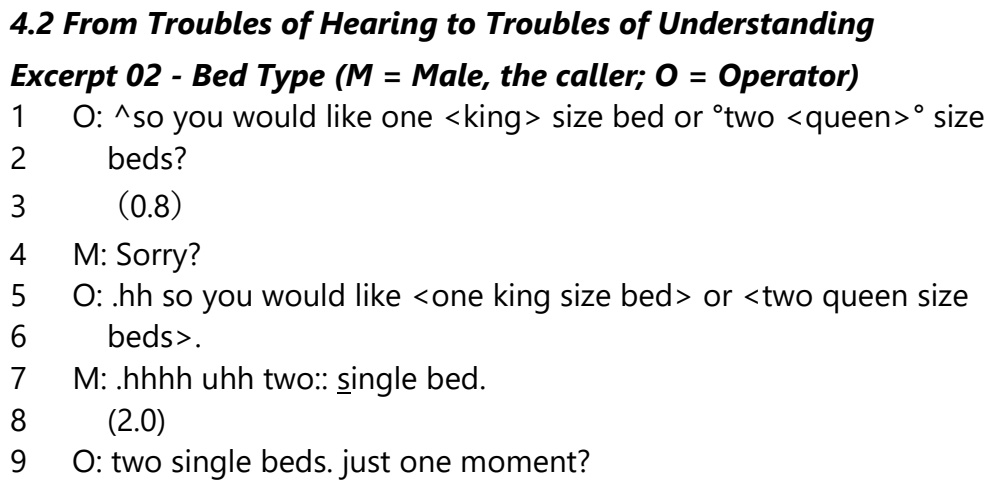

In lines 1-2, the operator wants to know the caller's favored bed types. Despite the operator's deliberate emphasis on the names of the bed types 'king' and 'queen' with stretching sounds, the caller fails to hear the question. To elicit a clarification, the male utilizes an open-class repair initiator (Drew, 1997) 'Sorry?' after a 0.8-second pause. Following that, the operator treats the trouble the caller encountered as a hearing problem. In this case, the operator makes a self-repair (lines 5-6) with devices repeating the 
trouble source in line 1 and lengthening the sounds of 'king/queen size bed'. Instead of selecting between the two types suggested by the operator, the male offers a candidate understanding in line 7. Looking together with the inhalation and the hesitation marker 'uhh', line 7 has elevated the trouble source of hearing to trouble source of understanding. With a long pause for 2 seconds, the operator realizes that the trouble is not from inadequate hearing but rather from the use of names that are unfamiliar to the caller. Interestingly, the operator concludes the information inquiry through accepting and repeating the male's alternate understanding 'two single beds' in line 9, rather than making another round of adjustment and repair.

In Excerpt 2, we see how the operator addresses the open-class other-initiated repair initiator when he/she identifies a hearing problem, and his/her concluding strategy (i.e., accepting/repeating the caller's candidate understanding) when there is an understanding problem. Basically speaking, the operator first treats it as a problem of hearing. After repair trials, the operator handles it as a problem of understanding. (S)he deals with the problems in different ways. In fact, Excerpt 3 demonstrates a similar case, where the operator is checking the membership with the male.

\section{Excerpt 03 - Member or Number (M = Male, the caller; 0 = Operator)}

1 O: ${ }^{\circ}$ so thank you for choosing our hotel $i^{\circ}$

$2(0.4)$

3 M: [yeah

4 O: $\left[^{\circ}\right.$ may $\wedge$ I know you are a (.) sands resort club member? ${ }^{\circ}$

$5 \quad(1.0)$

6 M: sorryi

$7 \quad(1.3)$

8 O: may $\wedge$ I know you are a <sands resort club > member?

$9 \quad(2.0)$

10 M: what number?

$11 \quad(2.0)$

12 O: .h > oh< it doesn't matter its our <sands resort club member $>$.

13 (.) if you are .hhh interested in ^ ${ }^{\text {it }}$ you ca:n regist $\left({ }^{\circ} \mathrm{er}\right)$ it

14 Aup on your check in.

The operator aims to check whether the male is a 'sand resort club member' in this conversation. It begins with the operator's acknowledgment and the male's confirmatory response (lines 1-3). An other-initiated self-repair, then, happens in lines 4-8. The operator makes the checking request in line 4. After a 1-second pause, the male initiates repair with the open-class initiator (Drew,1997) 'Sorryi'. Following another pause, the operator repeats his/her checking request with minor changes (i.e., stretching the phrase 'sands resort clubs'). Repeat here suggests that the operator regards the trouble to have resulted from a problem of hearing (Schegloff et al., 1977; Sidnell, 2010). Nevertheless, the 2-seconds pause in line 9 and the question 'what number?' in line 10 indicate that the caller doesn't make sense of "<sands resort club> member", but he tries to offer a candidate comprehending it as a kind of number since an inquiry of number from the hotel staff is common while booking a room. Based on it, the operator notices that the trouble has moved from hearing to understanding. Instead of making a repair, the operator directly drops the question and interprets the male's response as the unfamiliarity with their membership schemes (line 12). Besides, the operator offers a candidate solution to the male (lines 13-14).

Excerpt 3 resonates with the preliminary findings revealed in Excerpt 2, where the repetition is clearly responsive to problems of hearing at the beginning (Sidnell, 2010). Following this, another possible trouble type can be detected by the recipient. Similarly, the operator adopts the same concluding strategy of avoiding repair in this excerpt, but an additional candidate solution is provided here. In Excerpt 4, we look at how accepting a candidate's answer and avoiding repair is finished when the trouble of understanding arises.

\subsection{Troubles of Understanding}

Excerpt 04 - Mistakes Handling ( $M$ = Male, the caller; 0 = Operator)

1 O: comin on: (.) Friday? or Saturday?

$2(0.5)$

3 M: .h uh Friday.

$4 \quad(2.0)$

5 O: Friday (.) thirteenth? for how many nights?

$6 \quad(1.2)$

$7 \quad$ M: uh (.) ju- just my (.) just me.

$8 \quad(2.8)$

9 O: so one night? (0.2) one person. 
$10 \quad$ (1.0)

11 M: Yea ya.

$12(2.8)$

13 O: ${ }^{\circ}$ thank you. .hhh uhm:

In this case, the operator enquiries about the male's staying period. Initially, the operator asks and confirms the check-in date with the male in lines 1-5. However, the second portion of the operator's talk in line 5 makes the male have trouble understanding as indicated by the long pause and the irrelevant response (lines 6-7). Specifically speaking, the male uses repair devices cut-offs 'jujust' and pre-framing (i.e., 'my' is replaced by 'me, and 'just' is repeated.) to provide responses to the operator's question. After a long pause lasting 2.8 seconds, the operator in line 9 offers a candidate answer 'so one night' in the first portion of his/her talk and accepts and interprets the irrelevant response 'just me' as additional information 'one person' in the second portion of his/her talk. The male, then, articulates two particles 'Yea ya' (line 11) to confirm the repair finished in line 9.

In Excerpt 4, it is noteworthy that when there is a trouble of understanding, the operator directly offering a candidate and accepts the additional information the caller provides through his misunderstanding. To some extent, this strategy may have a close relationship with the tiny issue, the check-in date, discussed here. However, when the mistake or misunderstanding is critical and hard for the recipient to offer a candidate, the recipient is more likely to point out and repair it instead of accepting it or avoiding a repair. Such a situation can be exemplified in Excerpt 5.

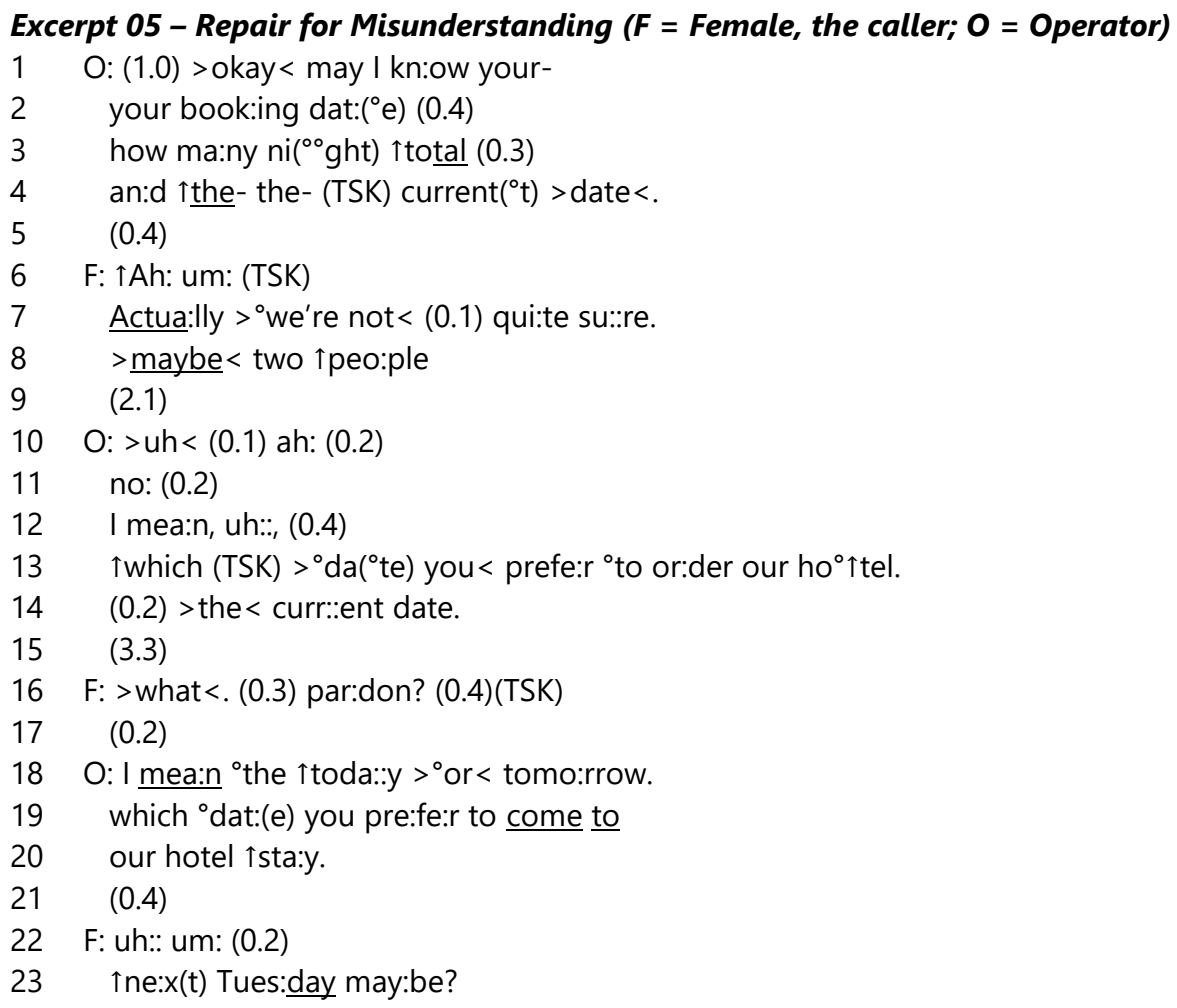

The operator confirms the check-in date during the conversation. Initially, the operator makes a request for information by asking a series of questions (lines 1-4). (S)he attempts to check the 'booking date' first, then downgrades it to details such as 'how ma:ny ni $\left({ }^{\circ} \mathrm{ght}\right)$ total" and "the- the- (TSK) current $\left({ }^{\circ} \mathrm{t}\right)>$ date.' However, the female makes a misunderstanding in lines 6-8. She utilizes the hesitation particles 'ah' and 'um' to take the turn, responding to the operator's request. Interestingly, she does not make repairs as she mistakenly thinks that the operator is checking the number of residents. Noticing the caller's misunderstanding and unexpected response, the operator first uses 'no' to directly point out the misunderstanding. Following that, the operator adopts the repair preface (Sidnell, 2010; Lerner \& Kitzinger, 2015) 'I mean' to clarify her own question, intending to repair the misunderstanding at the third position (Schegloff, 1992; Kitzinger, 2013). The caller then expresses her confusion after a long pause by asking, '> what<. (0.3) par:don?' From this open-class initiator, the problem of understanding is still visible to the operator. Again, the operator clarifies and makes repair by using the repair preface (Sidnell, 2010; Lerner \& Kitzinger, 2015) 'I mean' and replacement. It is also worth noting that the operator's explanation is gradually moved from the general 'which date' (line 13) to the specific and detailed ' ${ }^{\circ}$ the toda:::y > or tomo:rrow'(line 18). Finally, the caller's response 'ne:x(t) Tues:day'(line 23) solves this trouble of understanding. 
In Excerpt 5, we see how the operator makes the repair to elicit a relevant response from the caller. In this case, the source of the trouble of understanding is solved through several rounds of repair and repair initiations. Instead of making repair on the callers' interaction, the operator here continues to repair his/her own turn in order to clarify and solicit responses from the caller.

\section{Conclusion}

The present paper explores how repair is initiated and completed via phone in the service industry through the lens of conversation analysis. Data analysis here has revealed the following patterns: in Excerpt 1, the operator identifies the trouble source as hearing problem with repetitions when a direct request 'could you please be louder?' (lines 3-4) is made. In Excerpt 2 and Excerpt 3, the operator first handles the trouble source as a hearing problem when open-class initiators are used by the caller. It is only after this receives another round of response that the operator identifies it as a trouble of understanding. In this end, the operator directly accepts the candidate understanding provided and avoids the repair. Furthermore, the detailed analysis in Excerpts 4 and 5 discloses that the repair strategies involved are closely related to the importance of the mistake or misunderstanding.

To sum, repair is still potentially frequent and relevant in telephone conversations (Sacks, 1995). In the excerpts we have analyzed, one distinct repair feature is that the service personnel involved tend to either accept the customer's candidate understanding to avoid the repair or continuously make repairs on their own turns to clarify. In this sense, the customer examined here is highly valued and respected by the operators working in the service industry. Furthermore, this study showcases that Chinese English speakers frequently encounter troubles of understanding and hearing in phone conversations. To solve this problem, speakers adopt a number of cut-offs (e.g., 'ju- just' in Excerpt 4), hesitation markers (e.g., 'uh' in Excerpt 5), repair preface (e.g., 'I mean' in Excerpt 5), and open-class repair initiators (e.g., 'sorry' in Excerpt 2) to initiate repairs. Additionally, strategies as replacement and pre-framing are utilized to operate on words and phrases over the phone.

Such empirical evidence further supports and validates Kitzinger's (2013) idea that a) specific repair forms and practices are constrained by a range of local factors, and b) people adopt diversified methods and strategies to 'fix' troubles of hearing and understanding. Future studies, however, are suggested to conduct in other countries where English functions as an additional language to cross-verify findings reported in the present paper.

Funding: This research received no external funding.

Acknowledgments: The authors would like to express the deepest gratitude to Professor Younhee Kim and her TA for providing constructive comments on this project. Meanwhile, we want to extend our sincerest appreciation to Mohammad Amin Noori Mazandarani for his assistance in dictating the audio recordings. We are also grateful to the two participants and service personnel involved in the data collection stage. It also should be noted that there are no interests of conflicts between the authors and participants. However, all remaining errors in this paper are ours.

Conflicts of Interest: The authors declare no conflict of interest.

\section{References}

[1] Allen, D, E., \& Guy, R, F. (1974). Conversation Analysis: The Sociology of Talk. Mouton, Paris: The Hague

[2] Drew, P. (1997). "Open" class repair initiators in response to sequential sources of troubles in conversation. Journal of Pragmatics, 28(1), 69101.

[3] Dörnyei, Z. (2007). Research Methods in Applied Linguistics. Oxford: Oxford University Press

[4] Have, P, T. (2007). Doing Conversation Analysis (2 ${ }^{\text {nd }}$ edition). Singapore: SAGE publication.

[5] Hopper, R. (1992). Telephone Conversations. Bloomington: Indiana University Press.

[6] Hosoda, Y. (2006). Repair and relevance of differential language expertise. Applied Linguistics, 27(1), 25-50.

[7] Jefferson, G. (2003). A note on resolving ambiguity. In P. Glenn, C. Lebaron \& J. Mandelbaum (Eds.), Studies in Language and Social Interaction (pp.221-240). Mahwah, NJ: Lawrence Erlbaum.

[8] Kim, Y-h. (2018). Repetition with slight variation primarily through final particles in Korean-English bilingual children's interaction. East Asian Pragmatics, 3(1), 59-90.

[9] Kitzinger, C. (2013). 'Repair'. In J. Sidnell \& T. Stivers (Eds.), The Handbook of Conversation Analysis. Malden, MA: Wiley-Blackwell.

[10] Laakso, M., \& Sorjonen, M. (2010). Cut-off or particle - Devices for initiating self-repair in conversations. Journal of Pragmatics, 42(4), 11511172.

[11] Lerner, G, H., \& Kitzinger, C. (2010). Repair Prefacing in the organization of same-turn self-repair. Paper presented at the International Conference on Conversation Analysis, Mannheim, Germany.

[12] Lerner, G, H., \& Kitzinger, C. (2015). Or-prefacing in the Organization of Self-Initiated Repair. Research on Language and Social Interaction, 48(1),58-78.

[13] Liddicoat, A, J. (2010). Introduction to Conversation Analysis: Building Learning in Mathematics. New York: Continuum 
[14] Sacks, H. (1995). Lectures on conversation, 2 vols. Oxford: Basil Blackwell.

[15] Scarcella, R. (1988). Conversational analysis in L2 acquisition and teaching. Annual Review of Applied Linguistics, 9, 72-91.

[16] Schegloff, E.A, Jefferson, G., \& Sacks, H. (1977). 'The preference for self-correction in the organization of repair in conversation'. Language, $53,(361-82)$

[17] Schegloff, E, A. (1992). Repair after next turn: The last structurally provided defense of intersubjectivity in conversation. American Journal of Sociology, 97(5), 1295-1345.

[18] Schegloff, E, A. (2004). Lectures on Repair and Categorization (244b/266, Conversational Structures II). UCLA.

[19] Schegloff, E, A. (2007). Sequence organization in interaction: A primer in conversation analysis. Cambridge: Cambridge University Press.

[20] Sidnell, J. (2010). Conversation Analysis: An Introduction. Malden, MA: Wiley-Blackwell.

[21] Svennevig, J. (2008). Trying the easiest solution first in other-initiation of repair. Journal of Pragmatics, 40, 333-348.

[22] Wang, J., \& Zhang, H. (2021). Conversation Analysis and Second Language Pedagogy: A Guide for ESL/EFL Teachers (2 ${ }^{\text {nd }}$ edition). New York: Routledge.

[23] Wong, J. (2000). Repetition in conversation: A look at "first and second sayings." Research on Language and Social Interaction, 33(4), 407424.

[24] Wu, R. R. (2006). Initiating repair and beyond: The use of two repeat-formatted repair initiations in Mandarin Conversation. Discourse Processes, 41(1), 67-109. 